\title{
PESQUISA ARQUEOLÓGICA INICIAL EM PALMARES
}

\author{
Charles E. Orser, Jr* \& Pedro Paulo A. Funari**
}

\section{INTRODUÇÃO}

Após mais de um século sem a escravidão, as relações sociais no Brasil continuam a ser influenciadas pelo sistema escravista que existiu por séculos. As relações de trabalho são, ainda, ligadas à escravidão (Iokoi 1989:109) e preconceitos sutilmente racistas contra os negros continuam em vigor. A maioria dos negros não têm acesso aos níveis sociais mais elevados "simplesmente porque são negros" (Harris 1956:137). Neste contexto, a busca dos "povos sem escrita", no Brasil, (Wolf 1980:X) significa que a cultura negra deveria estar na base de qualquer revisão do passado. Os escravos raramente deixaram registros escritos e os documentos que existem são, muitas vezes, de dificil interpretação (Schwartz 1977, 1987:16). Desta forma, a cultura material fornece um meio de acesso direto à cultura africana nas Américas. A Arqueologia Histórica tem demonstrado, claramente, os avanços do estudo da cultura material afro em numerosos sítios, em particular em fazendas escravistas (Orser 1990; Funari 1991). Sítios fora dessas fazendas, especialmente quilombos, são bem menos conhecidos, embora não menos importantes.

- Midwestern Arqueological Research Center Illinois State, University Normal, Illinois 61761-USA.

* Depto. de História - Universidade Estadual de Campinas 13100 - Campinas.SP.

Estudos Ibero-Americanos. PUCRS, v. XVIII, n. 2, p. 53-69, dezembro, 1992 
Acampamentos de escravos fugidos, chamados maroons (Aptheker 1979:151), palenques (Escalate 1979:74) ou quilombos (Moura 1987), representavam uma das mais importantes formas de resistência ao escravismo nas Américas (Davidson 1979:82). Representavam "sem dúvida, a forma mais comun de resistência coletiva à escravidão" (Reis 1992:17). Quilombos espalhavam-se por todo o mundo das fazendas escra. vistas e surgiram já com o início do período colonial (Careno e Silva 1991). Muitos habitantes de comunidades quilombolas "desenvolveram habilidades extraordinárias na guerra de guerrilhas" (Price 1979:7) e foram capazes de desafiar as autoridades coloniais e, depois, nacionais. Muitas comunidades tornaram-se uma força de modificação das relações sociais, a nível local ou regional.

O maior e mais duradouro quilombo foi Palmares, no nordeste do Brasil (Degler 1971; Moura 1987). Ativo por quase todo o século XVII, no seu apogeu Palmares compunha-se de diversas aldeias com milhares de habitantes. Muitos estudos históricos foram escritos sobre Palmares (e.g. Freitas 1984 inter alios), mas esta comunidade foi pouco estudada por antropólogos e arqueólogos (Bastide 1978:83-90 constitui uma rara exceção). Desta forma, a maior parte dos aspectos culturais e sociais de Palmares continua obscura. Por exemplo, permanece uma incógnita as influências africanas, indigenas e européias na organização social. O ponto de vista tradicional considera que vivia "da mesma forma que viviam em Angola" (Boxer 1973c:140). Contudo, se nativos viviam em Palmares e interagiam com os fugitivos, como indicam as fontes escritas, então Palmares devia ser uma sociedade multi-étnica. De qualquer forma, mesmo os diferentes grupos étnicos africanos em Palmares não deviam ser descritos, simplesmente, como "africanos", mas, especificamente, como "do Congo", "Mbundu" ou por qualquer termo cultural apropriado (Haviser and DeCorse 1991:327). A etnicidade das populaçòes escravas é sempre difícil de determinar (DeCorse 1992:168) e, no caso dos africanos trazidos à América, os contatos com os indigenas implicava que mesmo traços culturais estáveis, como a religião, podiam sobre transformações mais ou menos profundas (Santos 1992).

A Arqueologia Histórica é a melhor maneira de estudar Palmares. A cultura material pode ajudar-nos a entender boa parte do que, hoje, permanece desconhecido sobre a vida cultural e social em Palmares. O estudo da cerâmica, por exemplo, pode fornecer informações únicas sobre estilos, formas e, talvez, até mesmo sobre as origens étnicas destes atributos. Além disso, todo o assentamento com suas casas, ruas, muralhas e jardins - podem indicar influências africanas, americanas (indigenas) ou européias ou, então, mostrar o caráter mesclado da cultura quilombola. Em suma, Palmares constitui um sítio particularmente fértil para o estudo de como escravos africanos fugitivos - longe de sua pátria - forjaram uma nova cultura ano sertão do 
Brasil e foram capazes de resistir por quase um século à repressão. Na medida em que as origens últimas de Palmares encontravam-se na resistência à escravidão, podemos aprender muito sobre como este grupo de africanos lutou contra a aristocracia escra. vocrata brasileira.

Em 1991, o Projeto Arqueológico Palmares foi criado para estudar Palmares através da Arqueologia Histórica. A primeira fase desta tarefa a longo prazo foi levada a cabo em 1992. Nosso objetivo, aqui, consiste em fornecer alguma informação preliminar sobre Palmares e descrever nosso trabalho de campo. Um relatório detaIhado já foi publicado (Orser 1992).

\section{UM BREVE HISTÓRICO DE PALMARES}

A partir de 1500 , os portugueses começaram a colonização do Brasil, procurando defendê-lo das pretensões francesas (Diffie 1987:31). Usaram, de início, mão-deobra escrava indígena e, em seguida, africana. Na capitania de Pernambuco, onde estava Palmares, talvez chegassem quase. 4.400 escravos africanos por ano (Hall, Harrison e Welker 1987:181). Estes escravos recém-chegados eram encaminhados para o trabalho nas fazendas costeiras de cana-de-açúcar. Em 1854, Pernambuco contava 26 usinas; em 1612, as capitanias do norte, incluindo-se Pernambuco, tinham 170 usinas; em 1627-1628, 230 usinas funcionavam no Brasil (Boxer 1973a:192).

Tendo surgido mais ou menos em 1605, Palmares localizava-se na Serra a oeste da costa do nordeste (Kent 1965:165). Os cronistas contemporâneos afirmavam que Palmares tinha sido fundado por "cerca de quarenta negros da Guiné" (Rocha Pita 1950:294), mas este termo étnico não significava qualquer precisão. Os portugueses, no século XVII, normalmente referiam-se aos africanos, em geral, como "da Guiné", termo sem especificidade suficiente (Hall, Harrison e Welker 1987:57; Kent 1965:165-166). Como quer que seja, os colonos europeus logo se familiarizaram com Palmares e, em 1612, os portugueses atacaram, pela primeira vez, o quilombo. Chamavam-no "Palmares" por causa das palmeiras mas seus habitantes, os palmarinos, ao que parece, referiam-se ao quilombo como "Angola janga" ou "Angolinha", em Português (Freitas 1984:9, Schwartz 1985:342).

Os holandeses, que estabeleceram-se na região em 1630 (Boxer 1973b:98-100), preocuparam-se com o crescimento de Palmares e, em 1640, enviaram um grupo para investigá-lo. Esta missão foi comandada por Bartolomeu Lintz, o primeiro europeu a descrever a comunidade. Lintz menciona dois assentamentos palmarinos: Grandes Palmares e Palmares Menores. Os habitantes destas cidadezinhas, "dedicavam-se a 
roubar os escravos dos portugueses" e viviam "de feijòes, cevada, cana-de-açúcar, aves domésticas e peixes" (Nieuhoff 1813:707).

Em 1964, uma expedição holandesa atacou os Grandes Palmares com uma força composta de indígenas, destruindo-os com "ferro e fogo" (Barleus 1923:370). Estes ataques holandeses, contudo, não tiveram impacto duradouro e Palmares continuou a crescer em tamanho e população (Barleus 1923:253; Drummond 1859:305).

No ano seguinte, Juergens Reijmbach comandou outro ataque holandês a Palmares. Reijmbach relata que a aldeia atacada tinha uma dupla paliçada defensiva. No interior, havia um fosso "cheio de estacas afiadas" (Carvalho, 1902:92; Carneiro 1988:256). A aldeia, sede do "rei" de Palmares, era descrita como tendo 220 casas, uma igreja, quatro forjas e uma grande casa para um conselho.

Entre 1670 e 1694 Palmares foi governado por um "rei", chamado "Ganga Zumba", ou Grande Senhor, que vivia na capital, Macaco, provavelmente o local atacado por Reijmbach. Esta aldeia seria chamada Macaco, em português, porque um símio teria sido, supostamente, morto ali (Drummond 1859:306). Parece inevitável a suposição que, por outro lado, este nome possa ter tido outras conotações, talvez associando os negros aos macacos.

Relatos de 1670 a 1694 contam que Palmares teria até 20.000 habitantes, espalhados em dez acampamentos. Estas aldeias chamavam-se Cerca Real (ou Macaco), Osenga, Subupira, Dambranga, Arotirene, Tabocas (com duas aldeias), Zumbi, Amaro e Andalaquituche (Tabocas (com duas aldeias), Zumbi, Amaro e Andalaquituche (Drummond 1859:304; Rodrigues 1945:131). As fontes do século XVII indicam que os palmarinos controlavam uma área que se extendia por 170 quilômetros (Drummond 1859:304), do rio Ipojuca, no atual Estado de Pernambuco até o rio Parába, no atual Estado de Alagoas (Moura 1987:35).

Os estudiosos modernos têm chamado estas aldeias de Palmares usando termos como "estado" (Carneiro 1988; Freitas 1984), "república" (Altavilla 1931; Ramos 1939; Kent 1965), "confederação" (Moura 1987) e "reino" (Curtin 1990:106). De qualquer forma, o elemento central de Palmares era seu caráter sincrético, pois "seu sistema político não deriva de um modelo específico africano, mas de diversos" (Kent 1965:175). Não se sabe quantas culturas estavam representadas em Palmares, mas Angola era a fonte da maioria dos escravos brasileiros no século XVII (Conrad 1986:28-29). Neste sentido, o comentário de Vieira, em 1648, de que "sem Angola nâo há negros" (Conrad 1986: IX) está correto. Angola, no século XVII, compunha-se de muitas culturas diversas (cf. Maestri 1978; Miller 1976; Thornton 1922; Vasina 1963) e esta complexidade cultural significa que Palmares era um "mosaico étnico e cultural" (Freitas 1984:39). 
Em 1670, os portugueses começaram uma investida séria para tentar destruir Palmares, enviando expedições quase anuais contra o quilombo. Em 1678, Ganga Zumba foi assassinado por seu sobrinho, Zumbi. A tradição mantém que Zumbi era mais guerreiro que seu tio, tendo pregado a resistência ativa aos portugueses em oposição aos compromissos defendidos por Ganza Zumba. A vitória de Zambi aumentou a tensão entre portugueses e palmarinos e, em 1694, uma força conjunta de indigenas e bandeirantes conseguiu destruir Macaco. Acabaram por capturar e executar Zumbi e dispersar os sobreviventes.

Hoje, Zumbi é celebrado como "o primeiro grande negro do Brasil" (Souza 1963:15) e suas façanhas são relembradas. Nos anos 1980 o Instituto Brasileiro de Patrimônio Cultural (IBPC) declarou Macaco, a capital de Palmares - na Serra da Barriga, Uniâo dos Palmares, Estado de Alagoas - um monumento nacional tombado. Isto ocorreu graças ao Movimento Negro, na medida em que os líderes negros perceberam a importância da luta dos antigos habitantes do quilombo contra a escravidão e a discriminação.

\section{O PROJETO ARQUEOLÓGICO}

Embora não seja fácil ter algum impacto na comunidade negra (Singleton 1988:364), já que a Arqueologia é, muitas vezes, considerada muito abstrata e elitista, concebemos o Projeto Arqueológico Palmares, desde o início, como Arqueologia Social no sentido mais amplo da palavra. Planejamo-lo, originalmente, como um meio de estudar a escravidâo, originalmente, como um meio de estudar a escravidão, o quilombismo, a exploração e as relações sociais, tais como refletidas na cultura material de Palmares, e procuramos fazer a história e a cultura de Palmares acessivel à sociedade brasileira. Funari co-dirige o trabalho de campo e é o responsável, diretamente ao IBPC, pelo sítio arqueológico, enquanto Orser co-dirige o trabalho de campo e é responsável pela administração do projeto. Ambos trabalham em estreita colaboração com Zezito de Araújo, que atua junto à população local, às autoridades e à comunidade negra em geral. Araújo, diretor do Núcleo de Estudos Afro-Brasileiros da Universidade Federal de Alagoas, tem estado à frente da luta em defesa da Serra da Barriga como um patrimônio nacional. Por fim, Michael Rowlands (University College London) é o africanista do Projeto e um parceiro na pesquisa. 


\section{A ETAPA DE CAMPO (1992)}

Nossa primeira etapa de campo em Palmares ocorreu em julho de 1992. O plano original previa localizar e pesquisar as dez aldeias de Palmares, datadas entre 1670 e 1694. Nossa pesquisa começou com um levantamento do sítio da capital, Macaco, na Serra da Barriga. A abundância do material em superfície, entretanto, tornou necessário limitar nossos esforços a este importante sitio. Nossa estratégia de pesquisa não pretendia localizar, sistemática e cientificamente, todos os sítios da Serra da Barriga. Ao contrário, nosso plano era simples: queriamos ver se, após 300 anos e grande atividade agrícola, seria possível encontrar restos de Palmares. Na medida em que encontrássemos sítios, nossa intenção era, simplesmente, coletar uma amostra representativa de cada um deles. Pensamos esta amostra apenas como um meio de demonstrar o tipo de fontes arqueológicas da Serra da Barriga e de avaliar a variedade de materiais disponíveis para futuros estudos.

A Serra da Barriga localiza-se no município de União dos Palmares, tendo cerca de 4.000 metros de leste a oeste e 500 a 1.000 metros de norte a sul. A serra está entre 150 e 560 metros acima do nível do mar e está na zona da mata alagoana (Araújo 1985:34-38). A fonte d'água mais próxima é o Rio Mandaú, cerca de 3.000 metros a leste, havendo numerosas fontes na serra. A cidade de Uniâo dos Palmares está do outro lado do rio, a 4.500 metros da costa leste da Serra da Barriga.

O grupo de pesquisadores, composto dos autores, Rowlands e voluntários do Brasil e dos Estados Unidos, encontrou dez sítios arqueológicos durante a campanha de 1992. Encontramos estes sítios através do levantamento de superfície e da indicação dos habitantes, posseiros da Serra da Barriga. Coletamos um total de 799 artefatos usando um método de coleta não-científico. Não coletamos todos os artefatos superficiais, selecionamos una amostra significativa da variedade de materiais presentes. A seguir, apresentamos uma breve descrição de cada sítio.

\section{Sítio 1}

A área designada como sítio 1 é, hoje, a área do monumento da Serra da Barriga. Uma grande estátua de Zumbi ai se localiza e este é o local de uma comemoração anual da comunidade negra e local, celebrando a memória de Zumbi e do quilombo dos Palmares. Este sítio está no topo, perto da ponto mais alto da Serra. Este localiza-se a sudoeste do sítio. 
Considerando-se que esta área é aceita, em geral, como sendo a principal zona de colonização do Macaco, e porque há grande quantidade de material cerâmico em superfície, decidimos levar adiante um programa de testes sistemáticos, no subsolo, a fim de obtermos informações básicas sobre a extensão, natureza e estado de preservaçâo do sítio arqueológico. Nossa estratégia de teste consistiu de quatro transeptos nas quatro direçôes cardiais a partir de um ponto central localizado 50 metros adiante do monumento (base de mastros de bandeiras). A cada dez metros efetuamos testes com uma pá. seguindo as linhas dos transeptos.

Além de recolhermos muitos fragmentos cerâmicos nestes testes, descobrimos duas importantes evidências, no sítio 1. No limite leste do sítios decidimos escavar uma trincheira em um acúmulo de terra recente. No fundo desta trincheira encontramos dois fossos na direção norte-sul. O fosso a oeste media 70 centímetros de largura e 30 a 40 centímetros de profundidade. Os fossos estavam distanciados cerca de 135 centímetros. Observamos um possível buraco de uma pilastra a leste, embora não fosse possivel examinálo em detalhe devido à estreiteza da trincheira. Quarenta metros na linha norte encontramos uma segunda descoberta interessante. Aqui, 40 centímetros abaixo da superfície atual, encontramos um grande vaso cerâmico intacto. Este media cerca de 71 centímetros de diâmetro e 69 de cumprimento. A espessura do vaso era cerca de 3 centímetros. Encontramos terra no interior do vaso e fragmentos cerâmicos no fundo. No solo, no topo do vaso, encontramos um vasinho, frag. mentado mas completo. Este era fino ( 0,54 centímetros), negro, baixo e achatado, com paredes inclinadas e lábio marcado. O diâmetro do lábio foi calculado como cerca de 36 centímetros.

Dois machados líticos apareceram associados ao grande vaso. Ambos foram encontrados na parte externa superior do vaso em posição vertical com suas pontas para baixo. O menos estava na face norte do vaso e media 9,24 centímetros de comprimento, 5,17 de largura e 3,48 de espessura. O segundo estava a leste-sudeste e não é tâo liso quanto o outro, medindo 15,83 centímetros de comprimento, 6,88 de largura e 5,24 de espessura.

Uma interpretação da função deste vaso, pelo momento, é difícil. Nossa primeira idéia foi que este vaso representasse uma urna funerária indígena. Estas urnas são bem conhecidas (Meggers 1948:159) e os habitantes da Serra da Barriga relatam que encontraram uma urna similar contendo em esqueleto humano e um colar. A presença de fragmentos semelhantes aos do vaso escavado por toda a área do sítio 1 significa que o platô pode ter servido como um cemitério pré-histórico ou, até mesmo, histórico, de caráter indigena. Meggers e Evans (1983-316) apresentam uma urna funerária 
piriforme, da tradição Aratu, datado de c. 800 d.C., semelhante ao nosso vaso. Ressaltam os autores que tais vasos foram encontrados no nordeste, inclusive em Alagoas, em cemitérios "contendo mais de 100 urnas" (Meggers e Evans 1983:317).

Por outro lado, a presença de 31 fragmentos cerâmicos, no fundo do vaso, torna possivel sugerir que este vaso pode ter servido para o armazenamento alimentar ou de outras coisas. Os fragmentos poderiam representar, neste caso, o resultado de depósito e retirada de substâncias do vaso. Vasos eram usado pelos Mbundu ou Ovimbundu, na Angola moderna, para o armazenamento de alimentos (McCulloch 1952:15). Um vaso ilustrado por Hambly (1934:368, prancha XIV), no seu estudo etnográfico dos Mbundu, tem a mesma forma do vaso do sítio 1, mas deve admitir-se que esta forma é comum em muitas regiões do globo e a semelhança pode ser meramente casual.

\section{Sítio 2}

O sítio 2 localiza-se a cerca de 100 metros a nordeste e ladeira abaixo, do sítio 1, aparecendo como uma ampla área de dispersão do mesmo tipo de cerâmica co. mum presente no sítio 1. Fomos levados a este sítios pelos moradores que, por razões pouco claras, referiam-se ao sítio como um "forno". Uma grande quantidade de fragmentos aparecia em superficie, sendo que decidimos recolher somente uma peça decorada. Este fragmento, uma alça cinza, tem a espessura de 0,57 centímetros. Quatro sinais retangulares aparecem na sua superficie.

\section{Sítio 3}

O sítio é um dos mais importantes encontrados nesta campanha de $1992 \mathrm{e}$, por isso, devemos tratá-lo mais detalhadamente. O sítio localiza-se no caminho para o topo mais elevado da Serra, 400 metros a sudoeste do sítio 1.

De início, coletamos 19 fragmentos cerâmicos em superficie. Esta coleção é importante porque inclui três tipos de vasos: comum; majólica vidrada; cerâmica torneada não vidrada. A cerâmica comum pode ser dividida em quatro tịpos. $\mathrm{O}$ primeiro é uma cerâmica fina ( 0,56 centímetros de espessura), temperada e marrom. Um fragmento é decorado com duas linhas paralelas de retangulinhos que deviam rodear todo o vaso. Um segundo tipo também é marrom e fino $(0,69 \mathrm{~cm})$ mas sem têmpera superficial. Um fragmento de lábio tem um ângulo aberto o que indicaria 
tratar-se de um diâmetro da boca total de cerca de $20 \mathrm{~cm}$. Um terceiro tipo é representado por uma alça completa, também marrom, com leve têmpera, podendo ser considerada, por certos analistas, como uma louça de barro. A espessura máxima é de $1,21 \mathrm{~cm}$. e um sulco lateral marcava a alça. Um quarto tipo é representado por três pedaços de um vaso grosso $(2,45 \cdot 2,79 \mathrm{~cm}$.) com um largo e marcado lábio. Estes fragmentos têm cor de canela, penderido para o vermelho.

O segundo tipo cerâmico encontrado no sítio 3 consiste em fragmentos de majólica. Nenhuma das peças encontrada neste sítio pode ser considerada a majólica fina comum em museus de todo o mundo. Estas, ao contrário, parecem ser de natureza utilitária. Encontramos apenas um fragmento decorado. Esta peça, provavelmente de um vaso grande, tem um vidrado verde amarelado no interior e é decorado com duas faixas paralelas avermelhadas. O exterior é desprovido de polimento. Os outros fragmentos de majólica representam três formas de vaso. A terceira forma é um pequeno vaso redondo, com um diâmetro calculado em 17 centímetros, com um pequeno lábio. Este vaso tem um vidrado desigual, de um verde amarelado ao pálido, mas com um lábio mais marcado. O vidrado do fragmento é amarelo, embora extendendo-se em todo o interior do vaso, extende-se apenas até o lábio no exterior. A terceira forma é um vaso mais grosso e amplo, com um diâmetro provável de cerca de 34 centímetros. O vidrado, neste fragmento, é visível apenas no interior.

O terceiro tipo é, talvez, o mais interessante porque é, até o momento, desconhecido. Este é de cor de canela, com um corpo trabalhado, sem vidrado, com um acabamento cuidado. Dois lábios diferentes aparecem nesta amostragem. O primeiro tipo tem uma borda simples, direta, arredonda. Dois fragmentos parecem vir de vasos de diâmetro estimado em cerca de 22 centímetros. Ambos são escurecidos na altura do lábio. A segunda forma, também representada por dois fragmentos, é de tipo singular, mas também apresenta um bordo arredondado. São, igualmente, escurecidas na altura do lábio, e parecem representar vasos de cerca de 18 centímetros de diâmetro. Fragmentos de base do mesmo tipo de vasos indicam que estes tinham bases planas. A filiação étnica desta cerâmica é desconhecida, mas pode representar uma combinação de tradições cerâmicas americanas e africanas.

Para entender a distribuição espacial dos artefatos neste importante sítio, dividímo-lo em cinqüenta quadrados de cinco metros cada e sistematicamente coletamos todos os artefatos, dentro de cada quadrado. Achamos $94 \%$ dos artefatos junto ao caminho que corta a roça de mandioca que alojava o sítio. Esta distribuição sugeriu que o sítio pode ter sido "criado" pelos moradores atuais que, ao encontrarem artefatos indesejados durante o cultivo, devem tê-los jogados fora, no caminho. Param testar esta hipótese, decidimos escavar uma área de 2 por 1 metro, no caminho. 
Encontramos dois pequenos buracos e 132 peças de cerâmica. Os três tipos de vasos - simples, majólica vidrada e vasos finos nào vidrados - estavam claramente associados nestes locais. A ocorrência simultânea destes tipos cerâmicos sugere que eram contemporâneos. Por extensão, esta descoberta significa que o grande vaso encontra in situ no sítio 1 pode ser contemporâneo à majólica colonial. Significaria, por sua vez, que a grande urna seja do período colonial.

\section{Sítio 4}

O sítio 4 consiste em um conjunto de artefatos adjacentes a um dos dois lagos da Serra da Barriga. Localiza-se a cerca de 150 metros, a noroeste, do sítio 3, mas a uma altitude bem menos elevada. Coletamos apenas oito peças deste sítio. Os frag. mentos cerâmicos representam sete tipos de vasos, agrupáveis em grossos e finos. Três peças espessas representavam duas variedades cerâmicas. Uma é cinza, ampla, com espessura máxima de $1,09 \mathrm{~cm}$. O segundo tipo tem um exterior cinza, interior escurecido, com espessura de até $1,60 \mathrm{~cm}$. A superfície é extremamente áspera. Cinco tipos de vasos de paredes finas aparecem no sítio. O primeiro é terracota vermelha, com espessura máxima de $0,72 \mathrm{~cm}$., com superfície exterior lisa. O segundo tipo é representado por um fragmento de lábio, cor de canela avermelhada, con espessura máxima de $0,52 \mathrm{~cm}$. e com uma superficie externa lisa. O terceiro tipo é cinza avermelhado, com espessura de $0,52 \mathrm{~cm}$. e superficie exterior lisa e escurecida. O quarto é cor de canela, com espessura de até $0,52 \mathrm{~cm}$., e superfície exterior lisa. O quinto é amarelo, com espessura de $0,41 \mathrm{~cm}$. e superficie externa lisa.

\section{Sítio 5}

O sítio 5 consiste de um amplo conjunto de artefatos espallados, ladeira abaixo, a partir do sítio 1. Pode relacionar-se aos sítios 1 e 2 . Apareceram quatro tipo de cerâmica. O primeiro é de corpo liso e talvez seja torneado, como parede fina $(0,59$ $\mathrm{cm}$.), interior de vermelho a preto a exterior de vermelho a cinza. O segundo é fino $(0,69 \mathrm{~cm}$.), pouco elaborado e marrom. O terceiro é representado por dois estilos diferentes de lábio. Tem um interior com de canela e um exterior escurecido, variando de $0,72 \mathrm{a0,78} \mathrm{cm}$. de espessura. Um perfil de um lábio é de ângulo agudo, enquanto o outro é reto. O quarto tipo é semelhante ao anterior, mas com uma forma sui generis. A peça coletada é um fragmento de uma borda de um cilindrinho, talvez 
um cachimbo ou um gargalo de garrafa, com somente quatro centímetros de diâmetro. O lábio é arrendondado e há marcas evidentes do uso do torno, no interior.

\section{Sítio 6}

Este sítio localiza-se perto do segundo lago, no lado oeste da Serra da Barriga. Coletamos apenas quatro peças cerâmicas, provavelmente de um único tipo. Dois fragmentos sâo finos (0,39-0,65 centímetros), de cor de canela, com o corpo liso. Um terceiro fragmento também tem um corpo liso, fino $(0,56 \mathrm{~cm}$.) mas é escurecido tanto no interior como no exterior. A última peça é um fragmento de lábio de um vaso com parede reta. O lábio é arredondado, de cor de canela, bem acabado, com espessura de $0,51 \mathrm{~cm}$. e o diâmetro da boca devia ser de cerca de $14 \mathrm{~cm}$.

\section{Sítio 7}

O sítio 7 localiza-se entre os sítios 5 e 6 , na parte oriental da Serra da Barriga, 100 metros a sudoeste de ladeira abaixo, em relação ao sítio 5 . Coletamos apenas um fragmento, neste sítio. Esta peça é um fragmento cerâmico arredondado, com exterior vermelho e interior cinza. Este fragmento é de forma oval, com espessura de $1,39 \mathrm{~cm}$. Sua função permanece desconhecida.

\section{Sítio 8}

Este sítio localiza-se no lado leste da Serra, cerca de 400 metros a este-nordeste do sítio 6. Coletamos apenas seis fragmentos cerâmicos, representando três tipos diferentes. O primeiro, com dois fragmentos, é mesmo tipo comum e espesso encontrado em toda parte, na Serra da Barriga. Estes fragmentos têm um exterior vermelho, o interior cinza, com espessura máxima entre 1,01 e 1,04 cm. O segundo tipo, com três fragmentos, é fino $(0,71-0,81 \mathrm{~cm}$.), vermelho. O último tipo é fino $(0,41 \mathrm{~cm}$.), com paredes lisas, com o exterior escurecido e o interior avermelhado. 


\section{Sítio 9}

O sítio 9 localiza-se a cerca de 300 metros norte do sítio 7 . Os quatro fragmentos cerâmicos deste sítio dividem.se em três tipos. O primeiro tipo é fino $(0,56 \mathrm{~cm}$.), liso, vermelho, representado por um lábio. Este lábio reto contém impressões de dedo, em direção ao exterior, por cerca de $2,15 \mathrm{~cm}$. O diâmetro da boca calculada para este vaso é cerca de 18 centímetros. Fragmentos semelhantes aparecem no quintal dos moradores perto do sítio 1 , podendo ser modernos. O segundo tipo é mais grosso $(0,70 \mathrm{~cm}$.), cinza, de um lábio arredondado. É bem acabado e calcula-se o diâmetro da boca em 26 centímetros. Dois fragmentos são finos $(0,42 \mathrm{~cm}$.), de interior cor de canela, exterior cinza escuro.

Além dessas produções aparentemente locais, encontramos, igualmente, cerâmica moderna. Uma das peças era a base de uma xícara de chá (louça). O lábio está bem desgastado, sugerindo uso prolongado do vaso. A peça apresenta uma marca, S. Paulo, em verde. O segundo fragmento é um lábio, provavelmente do mesmo vaso, decorado no exterior com uma faixa verde perto da borda e parte de uma flor verde e púrpura, ao lado. A última peça é um fragmento de cerâmica comum, sem vidrado. Os dois fragmentos de louça datam do século XIX ou XX mas o outro fragmento pode ser um pequeno pedaço de majólica colonial.

\section{Sítio 10}

O sítio 10 é o mais oriental, sendo uma superfície com cerâmica espalhada em uma roça perto da estrada da Serra da Barriga a Uniâo dos Palmares.

Coletamos apenas quatro peças cerâmicas, divisiveis em três tipos. O primeiro é um lábio curvo, com a borda arredondada. O fragmento é vermelho, com diâmetro máximo de $0,54 \mathrm{~cm}$. A boca devia ter cerca de 18 centímetros. O segundo também é um lábio, marrom, liso, espesso cerca de $0,61 \mathrm{~cm}$. $\mathrm{O}$ vaso era reto, com uma boca de diâmetro de cerca $22 \mathrm{~cm}$. Um terceiro fragmento tem a mesma espessura da segunda peça, mas tem o interior e o exterior escurecido. A última peça coletada é cor de canela, pendendo para o cinza, com acabamento liso e cerco escurecimento. Parece ser uma alça de um vaso grande. 


\section{CONCLUSÕES}

Nossa pesquisa inicial na Serra da Barriga, embora modesta na dimensão e nos objetivos, foi um grande sucesso. O Projeto Arqueológico Palmares forneceu importantes informações novas sobre o caráter arqueológico da Serra da Barriga, local considerado pela tradição como sede do último acampamento quilombola, onde ocorreu a batalha final contra os palmarinos. Localizamos dez sítios arqueológicos antes não identificados, coletamos 799 artefatos, tendo localizado centenas mais. Este material esta guardado no Museu Théo Brandão, em Maceió, sob controle da Universidade Federal de Alagoas.

Dos artefatos coletados, apenas 13 vieram de locais que não pudemos definir como sítios arqueológicos. Estes foram coletados de uma lixão moderno no quintal de um morador. Coletâ-mo-los para efeitos comparativos, a fim de usar como amostra para reconhecer os tipos cerâmicos modernos ainda em uso na Serra. A grande maioria dos artefatos (95,3\%) vieram dos sítios 1 (63,4\%) e $3(31,9 \%)$. Devemos reafirmar que nossa estratégia de coleta não buscava uma validade amostral estatística. Todos os sítios, com a exceção do sítio 3, foram amostrados criteriosamente. O sítio 2, por exemplo, continha centenas de fragmentos cerâmicos mas coletamos apenas uma peça. É evidente que uma estratégia de coleta sistemática e controlada teria fornecido mais material mas, provavelmente, não alteraria o quadro geral obtido a respeito do caráter arqueológico da Serra da Barriga. Para esta primeira etapa de pesquisa, nossa estratégia foi capaz de fornecer informações apropriadas e adequadas.

Demonstramos que há uma grande variedade de tipos cerâmicos na Serra da Barriga. Nâo tínhamos nenhuma predileção pela coleta de cerâmica mas, com a exceção do sítio 9, que continha uma peça de ferro, corroída, este foi o material encontrado. Nossa análise sugere a existência de, ao menos, três grandes classes de cerâmica, na Serra. O primeiro tipo é sem vidrado e era manufaturado usando-se uma técnica de rolinhos; apresenta diversos tipos e subtipos em várias formas de vaso. $\mathrm{O}$ segundo grande grupo é sem vidrado, bem trabalhado, na forma de vasos rasos. Usavam-se as técnicas dos rolos, do torno e do molde. O último grande tipo é a majólica colonial (porcelana). Esta tem vidrados amarelados ou esverdeados e eram produzidos em massa em fábricas, localizadas na Europa, possivelmente em Portugal, na Holanda ou, talvez até mesmo na Espanha. Pode ser significativo que nâo encontramos cerâmica pintada tão típica dos sítios pré-históricos do nordeste (Meggers e Evans 1983; Laroche e Laroche 1982). Esta evidência negativa pode significar que toda cerâmica que encontramos era do período histórico. 
Mais importante do que o número de tipos cerâmicos presentes no sítio histórico do Macaco é a idéia que estas diferentes classes representam "algo" sobre o passado. A questão é, obviamente, precisamente "o quê" representam? As diferenças observadas na cerâmica podem ser atribuídas a diferenças de data (pré-histórica e histórica), de etnia (ameríndia, africana, angolana, bundu, portuguesa, holandesa), de função (cozimento, armazenagem, enterramento), de gosto (cerâmicas vermelhas versus negras), de caráter simbólico (escravo ou livre, religiosa ou secular), ou outras particularidades. Infelizmente, nossa pesquisa preliminar não visava responder a estas importantes questões. Por outro lado, abrimos um novo capítulo no estudo de Palmares e de seus habitantes, escravos fugidos que combateram a escravidão e encontra. ram a liberdade nas montanhas do nordeste brasileiro. A continuidade de nossos esforços científicos poderá nos permitir investigar, no futuro, estas questões mais profundas e importantes.

\section{AGRADECIMENTOS}

Este trabalho foi originalmente apresentado como parte de uma mesa-redonda sobre "Portugal na era dos Descobrimentos", na reunião anual de 1993 da Sociedade de Arqueologia Histórica, em Kansas City, Estados Unidos. Gostaríamos de agradecer a Robert Hoover pelo convite a participar da sessão. Estamos particularmente em divida para com Zezito de Araújo, diretor do Núcleo de Estudos Afro-Brasileiros da Universidade Federal de Alagoas, em Maceió, e a Clóvis Moura, presidente do Instituto Brasileiro de Estudos Africanistas, em São Paulo. Recebemos informações ou discutimos temas tratados aqui com Mary Francisca do Careno, Christopher DeCorse, Robert Dirks, Mark Leone, William Marquardt, João José Reis, Anna C. Roosevelt, Michael Rowlands, Julie Ruiz-Sierra e Jocélio Teles dos Santos. Janice Louisa Orser e Raquel dos Santos Funari comentaram o manuscrito. A pesquisa relatada neste trabalho foi possível graças ao apoio institucional da National Geographic Society (Comitê de Pesquisa, processo número 4805-92) e pela Fundação de Amparo à Pesquisa da Universidade Estadual de Illinois.

\section{OBRAS CITADAS}

ALTAVILLA, Jaime de 1931 O quilombo dos Palmares. São Paulo, Cia Melhoramentos. 
APTHEKER. Herbert 1979 Marrons within the present limits of the United States, in Maroon societies: rebel slave communities in the Americas, 2nd. ed., ed. por Richard Price, 151-167, Baltimore, John Hopkins University Press.

ARAÚJO, Zezito de (org.) 1985 Serra da Barriga: exposição de motivos para o tombamento. Macejó, Núcleo de estudos afro-brasileiros, Universidade Federal de Alagoas.

BARLEUS. Caspar 1923 Nederlandsch Brazilie Onder Het Bewind van Johan Maurits, Grave van Nassau, 1637-1644. S.-Gravenhage, Martinus Nijhoff.

BASTIDE, Roger 1978 The African religioins of Brazil: toward a sociology of the interpretation of civilizations. Traduzido por Helen Sebba. Baltimore, John Hopkins University Press.

BOXER. Charles R. 1973a Salvador de Sá e a luta pelo Brasil e Angola, 1602-1686. Traduzido por Oliverio M. de Oliveira Pito. São Paulo, Cia. Ed. Nacional.

BOXER, Charles R. 1973b The Dutch Seaborne Empire, 1600-1800. Londres, Penguin.

BOXER, Charles R. 1973c The Dutch in Brazil, 1624-1654. Oxford, Clarendon.

CARENO, Mary F do e M.C.B.C. Silva 1991 Núcleos de resistência no interior dos Estados de Mato Grosso e São Paulo. São Paulo, manuscrito inédito.

CARNEIRO, Edison 19880 quilombo dos Palmares, $4^{\sharp}$ ed. São Paulo, Cia. Ed. Nacional.

CARVALHO, Alfredo de (tradutor) 1902 Diário do capitão João Blaer aos Palmares. em 1645, Revista do Instituto Arqueológico e Geográfico de Pernambuco, 10, 87.96.

CONRAD, Robert Edgar 986 World of sorrow: the African Slave trade to Brazil. Baton Rouge, Lousiana State University.

CURTIN. Philip D. 1990 The rise and fall of the plantation complex: essays in Atlantic history. Cambridge, Cambridge University Press.

DAVIDSON, David M. 1979 Negro slave control and resistance in colonial Mexico, 1519-1650, in Maroon societies: rebel slave communities in the Americas, 2a. ed., ed. por Richard Price, 82.106, Baltimore, John Hopkins University Press.

DECORSE, Christopher R. 1992 Culture Contact, continuity and change on the Gold Coast, A. D. 1400-1900, The African Archaeological Review, 10, 159-192.

DEGLER, Carl N. 1971 Neither black nor white: slavery and race relations in Brazil and the United States: Nova lorque. Macmillan.

DIFFIE, Bailey W. 1987 A history of colonial Brazil, 1500-1792. Flórida, Robert E. Krieger.

DRUMMOND, Conselheiro 1859 Relação das Guerras feitas aos Palmares de Pernambuco no tempo do governador D. Pedro de Almeida de 1675 a 1678, Revista do Instituto Histórico e Geográfico Brasileiro. 22, 303-329.

ESCALANTE, Aquiles 1979 Palenques in Colombia, in Maroon societies: rebel slave communities in the Americas, 2a. ed., editado por Richard Price, 74-81, Baltimore, John Hopkins University Press.

FREITAS, Décio 1984 Palmares: a guerra dos escravos. 5 a. ed. Porto Alegre, Movimento.

FUNARI, Pedro Paulo Abreu 1991 A Arqueologia e a cultura africana nas Américas, Estudos IberoAmericanos, PUCRS, 17, 61-71.

HALL, Frederik Arthur Holden, William F. Davidson e Dorothy Winters Welker (eds) 1987 Dialogues of the Great things of Brazil, attributed to Ambrósio Fernandes Brandão. Albuquerque, University of New Mexico Press.

HAMBLY, Wilfred D. 1934 The Ovimbundu of Angola. Anthropological series, Chicago, Field Museum of Natural History. 
HARRIS, Marvin 1956 Town and Country in Brazil. Nova lorque, Norton.

HAVISER, Jay B. e Christopher R. DeCorser 1991 African-Caribbean Intenaction: a research plan for Cruaçao creole culture, in Proceedings of the 13th International Congrese for Caribbean Archaeology. ed. por D. N. Ayubi e Jay B. Haviser. 326-337, Curaçao.

IOKOI, Zilda M. C. 1989 Trabalho escravo no Brasil atual, Revista de História, 120, 109-119.

KENT, R. P. 1965 Palmares: an African state in Brazil, Journal of African History, 6, 161-175.

LAROCHE, Armand F. G. e ADJELML Soares e Silva Laroche 1982 O sítio arqueológico de Mangueiros. Macaíba, Rio Grande do Norte, Recive, Editora Massangana.

MCCULLOCH, Merran 1952 The Ovimbundu of Angola. Londres, International African Institute.

MAESTRI, Mário José 1978 A agricultura africana nos séculos XVI e XVII no litoral angolano. Porto Alegre, Instituto de Filosofia e Cièncias Humanas da Universidade Federal do Rio Grande do Sul.

MEGGERS, Betty J. 1948 The archaeology of the Amazon Basin, in Handbook of South Anerican Indians, volume 3: the tropical forest tribes, ed. por Julian H. Steward. 149-166, Washington, Government Printing Office.

MEGGERS, Betty J. e CLIFFORD Evans 1983 Lowland South America and the Antilles, in Ancient South Americans, ed. por Jesse D. Jennings, 287-335, Nova lorque, W. H. Freeman.

MILLER, Joseph C. 1976 Kings and Kinsmen: early Mbundu states in Angola. Oxford, Claredon.

MOURA, Clóvis 1987 Quilombos: rrersistência ao escravismo. São Paulo. Ática.

NIEUHOFF, John 1813 Voyages and travels into Brazil, in A general collection of the best and most interesting voyages and travels in all parts fo the world, ed. por John Pinkerton, 697-881, Londres, Longman.

ORSER, Charles E. 1990 Archaeological approaches to New World plantation slavery, in Archaeological method and theory, volume 2, ed. por Michael B. Schiffer, 111-154. Tucson, University of Arizona Press.

ORSER, Charles E. 1992 In search of Zumbi: preliminary' archaeological research at the Serra da Barriga, State of Alagoas, Brazi. Normal, Midwestern Archaeological Research Center, Illinois State University.

PRICE, Richard 1979 Maroons and their communities, in Naroon societies: rebel slave communities in the Americas, 2a ed., ed. por Richard Price, 1-34, Baltimore, John Hopkins University Press.

RAMOS, Arthur 1939 The Negro in Brazil. trad por Richard Pattee, Washington. Associated publishers.

REIS, Joāo José 1992 Différences et résistances: les noirs à Bahia sous l'ésclavage, Cahiers d'Études africaines, 125,1534 .

ROCHA Pita, Sebastiāo da 1950 História da América Portuguesa. 3a ed Salvador, Livraria Progresso. RODRIGUES, Nina 1945 Os africanos no Brasil. 3a. ed. São Paulo, Cia. Ed. Nacional.

SANTOS, Jocélio Teles dos 1992 La divinité Caboclo dans le Camdomblé de Bahia, Cahiers d'Études Africaines, 125, 83-107.

SCHWARTZ, Stuart B. 1977 Rersitance and accomodation in 18th-century Brazil: the slaves view of slavery, Hispanic American Historical Review, 57, 69-81.

SCHWARTZ, Stuart B. 1985 Sugar plantations in the foundation of Brazilian society: Bahia. 1550-1835. Cambridge, Cambridge University Press.

SCHWARTZ, Stuart B. 1987 Mocambos, quilombos e Palmares: a resistência escrava no Brasil colonial. Estudos Econômicos, 17, 61-88. 
SINGLETON, Theresa A. 1988 An archaeological framework for slavery and emancipation, 1740-1880, in The recovery of meaning: historical archaeology of the eastern United States, ed. por Mark P. Leone e Parker B. Potter Jr, 345-370, Washington, Smithsonian Institution Press.

SOUZA, Yvonildo de 1963 Grandes negros do Brasil. Rio de Janeiro, Livraria São José.

THORNTON, John 1992 Africa and Africans in the making of the Atlantic World, 1400-1680. Cambridge, Cambridge University Press.

VANSINA, Jan 1963 The foundation of the kingdom of Kasaje, Journal of African History, 4, 355.374. WOLF, Eric R. 1980 Europe and the people without history. Berkeley, University of California Press. 